\title{
Creative Economy Teaching and Learning-A Collaborative Online International Learning Case
}

\author{
Aparna Katre ${ }^{1}$ \\ ${ }^{1}$ Department of World Languages and Cultures, University of Minnesota Duluth, USA \\ Correspondence: Aparna Katre, H487, 1201 Ordean Court, University of Minnesota Duluth, Duluth, MN 55811, \\ USA. E-mail: aukatre@d.umn.edu
}

Received: February 9, 2020

doi:10.5539/ies.v13n7p145
Accepted: March 14, $2020 \quad$ Online Published: June 25, 2020

URL: https://doi.org/10.5539/ies.v13n7p145

\begin{abstract}
Culture plays a central role in the creative economy, not only in terms of developing creative products and services but also in terms of shaping the processes by which products are crafted. Among various pedagogical approaches for the development of creative products, Collaborative Online International Learning (COIL) emerges as a promising vehicle. Educators can leverage audio, visual, and written communications technologies to connect learners from geographically distant cultures and place culture at the center of the creative product development processes. The University of Minnesota Duluth's introductory class on cultural entrepreneurship, CUE 1001, hosted a semester-long COIL project with Ocean University of China's Cultural Industries Management program to facilitate such innovation in cross-cultural teams. An ex-post evaluation of the project suggests that learners can appreciate the overall significance of culture when conceptualizing creative services and products. They develop an intercultural mindset and acquire the tools to work effectively in cross-cultural settings. Institutions of higher education can leverage COIL in a variety of domains, while studies comparing traditional and COIL-based approaches can further add to the body of knowledge regarding intercultural awareness and the internationalization of learning in higher education.
\end{abstract}

Keywords: collaborative online international learning (COIL), creative industries, creative workforce, intercultural awareness, internationalization

\section{Introduction: Culture and the Creative Economy}

The creative economy occurs at the intersection of creativity, culture, and organizations, and it is here that knowledge and skills about a wide variety of cultures are necessary for innovation to occur. Individuals and organizations participate in, and contribute to, the creative economy in many different ways: entrepreneurs, leaders, administrators, creators, producers, distributors, and businesses and nonprofit organizations. They create cultural value for players in the creative value chain that links creators, producers, distributors, and consumers. It is important to recognize that cultural value can take many forms (Holden, 2004): historical (in which relationships with the past come alive), symbolic (in the form of repositories of meaning such as honor, prestige, and freedom), aesthetic, spiritual, and social (where unity among people is emphasized).

Players in the creative economy are motivated by initiatives that help preserve current and historical paradigms of cultures, and which advance them, challenge them, or create new cultural paradigms (Davies \& Sigthorsson, 2013). Creative goods and services are, therefore, symbolic and embed meaning for those involved in the creative value chain; at the same time, goods and services are the objects of mass production and consumption. As suggested by various scholars (Davies \& Sigthorsson, 2013; Ginsburgh \& Throsby, 2006; Klamer, 2002; Unctad, 2010), creative products and services exhibit unique characteristics in that they:

- $\quad$ are experience-based, the taste for which grows as they are consumed in greater quantities;

- have some element of a public good; feature individual creativity;

- feature individual creativity;

- involve some form of intellectual property;

- possess forms of value which cannot fully be expressed in monetary terms; can inspire awe, wonderment and a sense of sublime; and 
- operate within a culture and define, bolster, and represent that culture.

Creative enterprises tend to differ from commercial enterprises in which economic value is prioritized over most other objectives. Creative enterprises, by contrast, prioritize the realization of cultural value and take into account the financial sustainability of the enterprise. As a result, their structures tend to differ from commercial enterprises. Pratt (2008) summarizes their characteristics this way:

- Most are small, medium, and micro-sized enterprises.

- Work processes cater to the rapid turnover of products, necessitating multiple simultaneous innovations to sustain the organizations.

- Market forms and regulations are mostly localized, reliant upon gatekeepers who control the wider distribution of creative goods,

- There are porous boundaries and mutually dependent relationships between nonprofit, for-profit, and public entities, as well as between the production and consumption processes.

Such enterprises employ disproportionately high numbers of creative professionals and require an organizational culture characterized by the following (Saintilan \& Schreiber, 2017, pp. 5-9):

- $\quad$ high tolerance of uncertainty regarding demand;

- $\quad$ expertise in risk and failure management;

- a deep connection to the products;

- relatively high creative autonomy;

- the capacity to integrate diverse skills; and

- the ability to work in a fast-moving, competitive environment.

Luckman (2013) argues that creatives in the industrialized world will find themselves functioning as sole proprietors working from contract to contract, or as employees in small, medium, and micro-sized enterprises where they are required to work in teams rather than as single individuals. Preparing such persons for this workforce demands greater attention to curricula and pedagogies that intersect with culture and identity, developing intercultural awareness and interpersonal communication competencies among creative workers.

One can conclude that culture plays a central role in not only the outputs of entrepreneurial activities (i.e., in the goods and services created), but also in the entrepreneur's approach to various activities in the creative economy. Andrew and Luckman (2015) suggest that teaching creative entrepreneurship must focus on working and communicating with other people. However, as regards creative industries, higher education curricula regarding creative industries lack the necessary focus on the intercultural aspects of the product development processes (Luckman, 2013).

\section{Pedagogies in the Creative Economy}

The creative economy is a new field of study with little systematic knowledge of pedagogies or their effectiveness already in place. Although this is an emerging field, scholars recognize the need to simultaneously teach students about the creative economy and provide opportunities for developing the relevant skills (Ashton \& Noonan, 2013; Gilmore \& Comunian, 2016; Harte, Long, \& Naudin, 2019; Levine \& Shtern, 2015; Luckman, 2013; Vecco, 2015). The latter involves pedagogical scaffolding whereby students reinforce their values and acquire the ability to continuously gain knowledge about the creative economy (in short, "learning to learn").

Commonly used pedagogical approaches represent experiential learning opportunities in the form of co-ops, internships, job shadowing, hands-on projects, problem-based learning, and learning in international teams. Examples of these are found in various sectors of the creative economy, such as print and digital media (Levine \& Shtern, 2015); performing, visual, and studio arts (Jacobs \& Rookus, 2015; Mahlangu, 2015; Strasser, 2015); design (Levick-Parkin, 2014); and heritage and conservation (Penna, Tinoco, \& Taylor, 2015; Zalewski \& Parowicz, 2015). Creative economy pedagogy scholars also emphasize the need to acquire knowledge and proficiency in digital technologies (Tafra, Skledar, \& Jemric, 2015), and to learn in international teams (Luckman, 2013). Creative economy academic programs emphasize learning about creativity, entrepreneurship, and the arts across such sectors as TV, video games, music, and fashion.

However, to the best of our knowledge and as supported by Luckman (2013), academic programs for the creative industries lack a focus on learning about cultures. Programs focusing solely on cultural industries or cultural economics, with emphasis on the core arts (performing, visual, and literary arts), may not sufficiently cultivate 
entrepreneurial mindsets or the necessary business skills. Other programs assume self-awareness about one's culture and the cultural assets that are crucial to conceptualizing new products and services. Creative industry programs and pedagogies that emphasize learning about cultures beyond the core arts themselves are lacking. As regards cross-cultural contexts, while Anglosphere universities attract a large number of international students, only a small share (less than 5\% in the United States) features humanities and the arts as their areas of study. Opportunities to have a meaningful international setting where students can develop intercultural competencies are few.

Furthermore, learning experiences where students focus on establishing an understanding of their own culture and those of other persons are scant. Examples in which learning about the creative economy is "situated" contextually, for example, only occurs in cross-cultural settings, especially in international teams which can help students learn about the creative economy (as most other programs do) but also, "learn in and with the cultures." Research and anecdotal evidence does suggest a reluctance to mix students from diverse cultural and linguistic backgrounds (Kimmel \& Volet, 2012; Summers \& Volet, 2008). Culturally diverse teams working on projects are better able to offer a unique, experience-based, individualized understanding of the role culture plays at both macro and micro levels, which deepens students' intercultural competencies.

When fields of study such as pedagogies relative to creative industries are nascent, Creswell (2009) suggests that it is necessary to accumulate knowledge through a wide range of case studies and qualitative studies. Therefore, case studies demonstrating cross-cultural contexts are uniquely positioned to expand knowledge. This paper presents findings from ex-post evaluation of a case study in which creative industry undergraduate students from the United States and China collaborated using synchronous and asynchronous communication technologies. We begin by describing the collaboration, the project design and execution, and an evaluation of the effectiveness once the project was completed.

\section{COILing Creative Economy Learning Experience}

\subsection{COIL for Intercultural Learning}

Internationalization has become a strategic priority for institutions of higher education that seek to diversify their student bodies and to enable students to compete, connect, and cooperate with peers from around the world. It calls for developing intercultural and international perspectives as a necessity, rather than as an option (Leask, 2013). It includes developing awareness of one's own culture as well as knowledge of other cultures, and learning to build on and work through the differences (Kahn \& Agnew, 2017). Bennett (2008) defines intercultural skills and competencies as "a set of cognitive, affective, and behavioral skills and characteristics that support effective and appropriate interaction in a variety of cultural contexts."

One of the approaches that leverage technological advancement towards this end is Collaborative Online International Learning (COIL). One description of this approach is as follows: "[It] is a model for teaching and learning that promotes the development of intercultural competence (the ability to communicate effectively and appropriately with people from other cultures) through a shared online multicultural learning environment." (For the excerpt, refer https://academics.cehd.umn.edu/digital-education/wp-content/uploads/2017/07/COIL-Workbook-July-20-2017.p df?pdf=coilworkbook).

COIL provides an opportunity for students to participate in intercultural learning without relying on travel or education abroad. It has continued to grow as an intercultural, instructional approach, particularly as institutions of higher education set about internationalizing their campuses. The online (synchronous and asynchronous) modes of communication across cultures, when designed well, can create opportunities for cultural exposure in which students reflect on their own cultural experiences and learn from those of their peers in a different region (Esche, 2018; Jie \& Pearlman, 2018; Toner, 2018). For these reasons, COIL is well-positioned as a learning approach for students studying creative industries and the creative economy. The author developed a COIL project for undergraduate students studying the creative economy.

\subsection{COIL Project in the Creative Economy}

Developing a COIL project is a collaborative process in which planning, instruction, and assessment are shared across two or more partner institutions (Jie \& Pearlman, 2018). The project and its ex-post evaluation reported here involves similar programs at two partner institutions of higher education: the Culture Industries Management (CIM) program at Ocean University of China (OUC) in Qingdao, China, and the Cultural Entrepreneurship (CUE) program at the University of Minnesota Duluth (UMD) in Duluth, Minnesota, U.S.A.

UMD's CUE program, launched in 2013, is among the first in the nation focused on developing an 
entrepreneurial mindset among undergraduate students as preparation for participating in the creative economy. In Summer 2014, the Chinese Prime Minister spoke of the need for "mass entrepreneurship and innovation," which was followed by a call by the Ministry of Education to deepen teaching reform. In Fall 2016, in response to these calls, the Literature and Journalism College of OUC set up the "Hai Chuang Space," which is integrated in their CIM curricula. This created a platform for cooperation between OUC and UMD.

\subsection{Partner and Project Development}

Faculty and administrators from UMD's CUE program and OUC's CIM program have worked collaboratively on significant initiatives that led to the COIL project: a joint UMD and OUC summer course taught at OUC, a dual degree arrangement between the two programs, and a summer study abroad program designed for students in UMD's Chinese Area Studies program. The COIL project was conceived with the goal of (1) providing collaborative learning opportunities for students who may not be able to travel abroad for education and (2) generating interest among OUC students regarding the dual degree possibilities. To this extent, the administrators and key program faculty from both institutions were committed to COIL.

It was decided to offer a new course that was identical to CUE 1001: Introduction to Cultural Industries and the Creative Economy. The motivations for this decision were twofold:

a) OUC faculty and students had experienced UMD's CUE program pedagogy in the joint summer class, which made them want more OUC students to experience it directly and holistically.

b) OUC found it difficult to accommodate the required structure and learning experiences with the pedagogy underlying other CIM courses. OUC preferred the slow exposure of their faculty to new pedagogy, allowing their faculty to become comfortable with it and subsequently incorporating COIL projects in existing classes.

Against this background, OUC announced a new course identical to UMD's CUE 1001 in Spring 2018. OUC students were encouraged to apply for the class and were selected based on their English proficiency. Faculty and teaching assistants at OUC and UMD who had participated in the joint summer class were chosen to ensure familiarity with the topic, course delivery, and pedagogy. At UMD, the course is taught each semester, and no special arrangements were necessary other than to set students' expectations that COIL is a significant component of the course. No selection criteria were applied, and the course was open to all students at UMD on a "first come, first served" basis (up to a specified enrollment cap). The COIL project component of the course involved OUC and UMD students organized in groups of four, two from each institution, working on projects for the duration of the course. The project constituted $55 \%$ of each student's grade, and each student on a team was expected to contribute equally to the project. OUC and UMD both viewed the COIL project as an additional step in developing the partnership between the two programs and their respective institutions.

\subsection{Timeline for the COIL Project}

The COIL course was scheduled for seven weeks from March 12, 2018, to April 30, 2018, although preparations began in early Fall 2017. A working document outlined the COIL project objectives, timetable, synchronous and asynchronous student activities, curriculum delivery, technology setup, and access to instructional materials. These are detailed in subsequent sections.

\subsection{Project Objectives}

The goal of the COIL project was to give students an experiential learning opportunity, encouraging them to innovate across cultures while developing intercultural awareness. Project activities involved students learning about their own cultures and those of their team members, as well as gaining an understanding as to how local cultures shape the creative economy at the macro and micro levels. While students at both OUC and UMD were learning about the creative economy through regular readings, lectures, and class activities, the project provided project-based learning as students developed innovative solutions to cultural issues.

Students searched for opportunities to solve cultural problems, generate solutions, and conceptualize business opportunities. Each of these steps required students to perform deep analysis of specific cultural issues using the PEST and SWOT analysis tools and to take macro perspectives of the issues into account. It also required students to regularly communicate synchronously during a designated class period each week, then asynchronously on their own time at various stages of the project. It included generating agreement on the specific cultural issue or topic for the project, understanding each other's innovative ideas, generating consensus on which idea to pursue, and, finally, synthesizing the information into a potential business idea.

The objectives of the COIL project were to see that students:

- recognized the central role of cultures and creativity in the creative economy; 
- appraised their potential to innovate in the creative economy by designing solutions for cultural issues;

- utilized knowledge of cultural resources and local heritages in creative ways to improve the social, economic, and environmental well-being of communities; and

- demonstrated a shift in their intercultural understanding.

\subsection{Technology}

Faculty and technical support teams at both OUC and UMD developed solutions for technology challenges that were identified over three months. The inability of various teams to access the same learning platform was identified as a constraint and, therefore, resulted in the creation of two separate localized platforms: Moodle at UMD and Blackboard at OUC. These were used to host course readings as well as audio-visual materials, and to manage assignments, submissions, and grading.

One-third of the class periods were delivered synchronously using WeChat/QQ. These tools were non-standard for UMD and, while the technical support team was deeply involved in its setup, lack of experience with the platform constrained the support team's ability to anticipate technology issues and plan for contingencies. Classroom requirements were defined for both OUC and UMD, and several connectivity tests were conducted involving students at both ends. A WeChat group was formed which included all students from both OUC and UMD, plus the instructors and teaching assistants. This WeChat group facilitated daily communications as a single class and worked as a platform to provide rapid answers to project-related questions. Additionally, WeChat groups (one for each student project, and including the teaching assistants) were formed to facilitate group-specific communications.

A schedule was established for each class period, and student interactions began with group icebreaker activities and cultural interviews, and were followed by three project-specific assignments. Student teams had to select a cultural topic from among such options as heritage and traditions, performing arts, visual arts, design, and tourism. Students were asked to also focus on one issue of their choice, preferably one relevant to both cultures (for example, a decline in millennials' interest in the performing arts).

\subsection{Project Approach and Activities}

The project was composed of three steps. First step and the related assignment involved applying specific analytical methods to research an issue, synthesize findings, generate unique insights and perspectives on the issue and summarize findings in a report. Second step and the attached assignment, required students to apply specific methods to develop creative responses to the issue, conceptualize a business model and develop a high-level plan of action. Finally, the third step focused on presenting the group project in class and to local community stakeholders via fairs held separately at OUC and UMD. Posters and presentations were developed in Mandarin and English promoting the team project. Throughout, students were asked to reflect on their experiences, learning, and performance working in cross-cultural teams. This integrated approach ensured that reflective approaches through written responses and subsequent class discussions underpinned the curriculum (Brockbank \& McGill, 2007, pp. 137-141). The assignments related to the three steps corresponded to $20 \%$, $20 \%$, and $15 \%$ of the course grade respectively.

\subsection{Ex-Post Evaluation of the COIL Project}

Students were expected to attain proficiency against predefined learning outcomes and the assignments and associated rubrics enabled formative and summative student performance evaluation. These were:

- It was intended that students recognize the central role that cultures and creativity play in the creative economy. The video portion of the assignment was the primary means for measuring this.

- Students were expected to accurately appraise their potential to innovate in the creative economy, designing innovative solutions to address cultural issues. It was expected that students would utilize knowledge of cultural resources and local heritages in creative ways, seeking to improve the social, economic, and environmental well-being of communities. These learning outcomes were assessed using various project-related assignments.

- Students were expected to demonstrate a shift in their intercultural understanding - an outcome assessed using surveys and individual reflection papers. (The survey was from the COIL handbook referenced earlier, developed and used in the COIL collaboration between Susan Coultrap-McQuin, SUNY Oswego, and Ina Pfeifer Issa, SUNY Empire State College in Lebanon, 2012-2014.) The survey was administered through Qualtrics during the last class and was both anonymous and optional.

For UMD students, proficiency relative to the learning goals were as follows: 
- $\quad \mathrm{D}$ and $\mathrm{D}+$ indicate proficiency level 1 ;

- $\quad \mathrm{C}-, \mathrm{C}$, and $\mathrm{C}+$ indicate proficiency level 2;

- $\quad \mathrm{B}-, \mathrm{B}$, and $\mathrm{B}+$ indicate proficiency level 3; and

- $\mathrm{A}+$ and $\mathrm{A}$ indicate proficiency level 4.

Once the course was complete, in May 2018, following data were extracted for UMD's program assessment reporting. The course and program assessment reporting followed UMD's peer-review procedures minimizing biases and preventing contamination of the data. Students' grades were aggregated at the assignment and course-level to report percentage of students at four different proficiency levels. Given the pedagogical novelty, excerpts illustrating varying levels of student learning outcomes were extracted from project assignments and reflections that were submitted in the course learning management system. During this extraction, no student identifying information such as name or student id was included as it was not relevant for project and program evaluation. The excerpts are a single file about two pages long with learning objectives and relevant quotes. OUC instructor provided a summary of student and faculty experiences. An ethics approval to reuse the data for this ex-post evaluation determined that the research is not human subjects related. Collectively, these data allowed us to perform ex-post evaluation of the COIL project. The excerpts were studied, important fragments of text were highlighted and the key themes they conveyed were captured. Simultaneously the survey data were analyzed for shifts in intercultural understanding and the proficiency levels analyzed for understanding of the creative economy. These were triangulated with the themes to arrive at findings. While the graded and closed-ended survey questions provided quantitative information, students' accounts provided thick descriptions and added texture to the claims of this work presented in the reflections section (Creswell, 2009).

\section{Reflections}

\subsection{Learning about the Creative Economy}

Assessment of the students' understanding of the creative economy, particularly the role of culture in identifying and developing opportunities in the creative economy, was conducted using both qualitative and quantitative data. Students' grades for various assignments indicate adequate proficiency for the first learning outcome and somewhat mixed outcomes for the second and third. These were as follows:

- Students were expected to recognize the central role of culture and creativity in the creative economy. All students who submitted the assignment exhibited proficiency levels of $3(33 \%)$ or $4(67 \%)$.

- For the other two learning outcomes, students accurately appraised their potential to innovate in the creative economy by designing innovative solutions for cultural issues; they also utilized knowledge of cultural resources and local heritages in creative ways to improve the social, economic, and environmental well-being of communities. Proficiency levels varied significantly: $53 \%$ at Level $4,12 \%$ at Level 3 , and $18 \%$ at Levels 1 and 2.

Proficiency Level 1 was found among students who, for various reasons, had ceased to participate in the project or had dropped the class. By contrast, Level 2 was generally attributed to students whose project teams took more time to become productive, and who missed a significant number of assignment deadlines. Narratives describing individual contributions, revealed students' level of understanding of the creative economy and helped explain the less-than-adequate performance of some students, especially concerning group project assignments early in the program.

Narratives do more than convey an understanding of the key role of culture in fostering creative industries: they demonstrate the deeper understanding acquired through online collaborative synchronous and asynchronous interactions. One student explained this way: "Through the time I spent with my American and Chinese classmates, I feel that I've developed a more thorough understanding of the roles creativity and culture play in an economic setting. People in China seem to put larger emphasis on subjects like math and science, rather than more expressive mediums like photography or music. This is obviously not a bad thing, as these values may just be due to the fact that they might not need cultural entrepreneurship to revitalize their industries yet."

Another student emphasized the centrality of ideas and communication: "From my experience with this class, and communicating ideas with other cultures, I can personally conclude that the creative economy is the exchange of ideas. Throughout the class, my team discussed their personal culture. This encompassed everything from the history and cultures of our cities to things like driving." Learning about the creative economies of North America and China through readings and lectures was supplemented by group discussions relating to teams' project ideas. This allowed students to not just "know about" the nature, size, and impact of the creative 
economies of these countries, but to also interpret "how" and "why" countries respond to common cultural issues differently, thereby producing different economic impacts.

Opportunities in the creative economy are anchored in culture and human creativity. Experiences of participants in the COIL class suggest that opportunities can arise from open discussions about each other's cultures, and through active search for problems that bear cultural significance for all team members. This is emphasized by this quote from a participant: "I sought to learn more about my Chinese teammates, about their city, their culture and daily lives. I learned that the Tibet region is also a popular tourist destination and is heavily polluted. This knowledge helped us develop our problem, tourism and pollution." When searching for opportunities, many students realized that the topic must bear cultural significance for every team member. A student cited an incident where his team had a disinterested member: "Our project topic was quite related to traditions and trying to keep them alive. [An American team member] was not interested in traditions and culture. He felt more along the lines of, if a tradition loses popularity, let it go. Had we found out sooner, we could have picked a different topic. It ended up making the whole project less fun and interesting to him. So one's values, particularly within the creative economy, are vital to consider lest one lose passion or interest."

A variety of courses served to expose students to analytical tools such as SWOT (which looks at the Strengths, Weaknesses, Opportunities, and Threats in a given situation) and PEST (looking at Political, Economic, Socio-cultural, and Technical factors). However, working in cross-cultural teams, there was a strong realization that, even though the problem and the tools at the highest level are the same, they can reveal unique insights about the problem when applied in specific cultural contexts. One team member commented as follows on the experience: "Even after we agreed on our problem, there were still many variables that came into play. For example, we unanimously agreed technology was an issue, and the American team decided that maybe [what would be appropriate would be] a phone application with a system that rewards the users with discounts [based on specific factors]...[but]after some conversations we figured out that Chinese government regulates [technology] much more than we do in the United States. This changed our idea a bit."

Similarly, students found that developing a shared understanding of the problem or the situation, especially when the collaborators have diverse cultural contexts, becomes all the more crucial. Developing an opportunity in the creative economy requires collaborators to share their vision and create a culturally accurate report regarding the combined knowledge of the team. As stated in their reflection, students realize that one's cultures and values can give different shapes to the same idea, and creating a shared vision requires constructive dialogue among the team members. One student observed this: "We researched this topic for weeks, and began to spread ideas on how the creative economy and [the project problem] related, and how it can be solved... In order to create and take initiation in activities, people must relate and understand each other's values. I knew that, to be successful, we needed to connect and understand our partners from China and their values."

Finally, students acknowledged that curiosity about other cultures is critical for creativity, and they mentioned that the output is much more creative when an intercultural collision is by design (as was the case in this COIL project). Here is how one Chinese student summarized the experience of learning about the creative economy in a cross-cultural team: "[The UMD instructor] changed the traditional teaching method and adopted the problem-solving method to motivate students to think. At the same time, she used the impromptu display section to push every student to think from their own perspective. When the linear thinking structure of Chinese students meets the net thinking structure of American students, valuable results also arise."

The value derived by Chinese students centered on the pedagogical aspects described above, and on the analytical tools and research methods that were useful in developing a comprehensive understanding of the creative economy. An OUC instructor remarked: "Students showed positive performance in the classroom, and used a visual way to demonstrate their understanding of social reality issues, which shows a great progress on their thinking and practicing." A final aspect of the pedagogy involved a semester-end fair in which OUC and UMD students presented their collaborative projects to audiences in their respective locations, defended their ideas, and received questions and a critique from the audience. A student described the environment at the fair as "a sea of joy," and the academic leaders, faculty, and administrators at OUC also seemed highly appreciative. As another Chinese student said, "The class undoubtedly strengthened my awareness of social issues, and has motivated me to solve social problems. It is important for each student of OUC to have responsibility for society."

\subsection{Intercultural Learning}

As summarized by the Chinese faculty and administration, the COIL experience created a "miniature landscape" for international exchange. It generated several insights for students, faculty, and administrators when working in 
intercultural settings. From the viewpoint of OUC faculty and staff, COIL projects have exposed students to new pedagogy, to problem-based learning in cross-cultural settings. For UMD faculty and staff, on the other hand, it has created a path forward for students who may not have the opportunity to study abroad, motivating such to study other languages and cultures.

Students' shifts in intercultural understanding revealed that, before this project, $46 \%$ of students had regularly interacted with persons from other nations; also, $40 \%$ had studied or traveled abroad for a few weeks, mostly to European countries and Australia. None had traveled to any Asian countries. The COIL experience favorably affected students' intercultural learning, as evidenced by the fact that $83 \%$ of students provided a response that was either strongly or somewhat in agreement with the attitudes queried. The responses suggested students were more aware of, and sensitive to, cultural differences and similarities after taking the course. They were better able to communicate and work with individuals with different cultural backgrounds, when first languages were not the same as theirs. They were also more interested in studying or traveling to other countries, and more open to interacting with persons from different national, cultural and religious or socioeconomic backgrounds. Finally, they simply demonstrated a greater interest in learning about global or international issues.

The results regarding two questions in the survey were somewhat surprising. First, 74\% of students indicated that they now felt differently about the need to speak more than one language. This is especially revealing given the current trend nationally and, more specifically, at UMD, where campus-wide there has been a decline in student interest in studying foreign languages and cultures. Previous explorations on this topic had indicated that students fear studying another language and perceive it hurts academic performance. There seems to be a widespread feeling among students that they lack the innate abilities to learn a foreign language, especially when it is for the first time at the university level, and that it represents a burden in the context of other academic work. With this context, the finding bears significance. Similarly, $22 \%$ of students indicated they would either not take, or would hesitate to take, an online collaborative course. Students' narratives indicate this is primarily due to the effort it takes to establish meaningful connections and overcome initial hurdles to forming productive relationships. Additionally, many students were challenged when it came to fitting offline interactions in their daily schedule, while some simply rejected the need to understand other cultures to have a productive work environment. Both these attitudes have profound implications, which are discussed later in the conclusions section of this paper.

One student made this statement: "If anything, this experience has provided me the necessary skills to interact with people of other cultures, as well as to relate to the struggles of one another." Another student, however, was open about his being intimidated by the COIL project: "This semester I learned a lot about what it means to be a part of a group with different thoughts and ideas being said back and forth. At first I was honestly a little intimidated...[It] was eye opening how different kids from the same generation can be."

The most effective approaches in such settings appear to be the following: being helpful, exercising patience during conversations, practicing humor to create a playful environment, being honest, finding common ground to appreciate differences, and utilizing icebreakers. For example, one student summarized his experience this way: "I found that when we got into a rough patch they were always so nice and helpful. I would say that the normal American student honestly wouldn't have been so cooperative, but with OUC students they were very patient and honest with us."

Commenting on how important icebreakers were, one student said this: "The [video] assignment really helped break the ice as far as cultural differences and similarities are concerned. It allowed us to open up a little bit and create an open environment to communicate, which led me learning multiple interesting things about China." Another student emphasized how shared experiences helped him and his teammates connect with different cultures. They found that knowing other's cultural practices (such as food, festivals, and sports) facilitated communications and helped establish a baseline of values from which to operate. It prevented each other from being misjudged or misunderstood. This quote clearly articulated these points: "All of the little tidbits of information that we talked about with each other [food, festivals, religion, schooling, history, etc.] really helped me to understand their side of things, and that was a crucial part of our project. That is because, without understanding their perspective, especially in the case of our project, we can't fully analyze and form our own perspective on the project."

A major lesson of the program might be summarized this way: it is important to be respectful of others' views and opinions, to neither stereotype nor demean their behaviors, and to dig deep to try to understand mental models and daily practices. A student spoke to this as follows: "[The experience] also helped to break down barriers and overcome stereotypes. A lot of times I can create stereotypes very easily. However, after this class I 
really realized how wrong that is of me to do. I think we all deserve to be able to express our beliefs and values to the world the way we want to. It is OK to be different. One should never stop practicing their beliefs due to society's judging them. " Another student learned the importance of understanding other people's communication styles, particularly in light of the perception that American students tend to be loud and participative (not shy about speaking in public), whereas Chinese students tend to take more time to formulate their thoughts (and, in effect, practice humility when speaking publicly). Students confident of their language skills would speak up. This excerpt is from one student's reflection:

"Working with students in a different culture not only was an amazing experience, but it really brought understanding of another culture...You can read about it on the Internet, but to actually experience it on a first-hand experience was unbelievable...[It] helped me to be more accepting of diversity. If you learn more about the how and why that each country became the way that they are, you can learn to accept rather than judge what makes them different...I was able to create more curiosity for other cultures. It made me more motivated to visit and find out what it is really like... [The experience] helped me build global awareness...being able to communicate in a kind and respectful way will go really far...At the end of the day, we all come from the same earth, breathe the same air, and drink the same water, even if it is on different parts of the planet. Finding common ground through understanding is essential in every avenue of life, and this class did a great job of exercising its importance."

\section{Conclusion}

Analysis of qualitative and quantitative data shows that collaborating in cross-cultural teams, supported by appropriate technologies for effective synchronous and asynchronous communications, can equip students to develop a deep understanding of their own and other people's cultures. Scholars have experimented with COIL projects in other contexts, such as in the arts (Kan, 2011), intercultural communications and rhetoric (O'Brien \& Eriksson, 2010), marketing (Jie \& Pearlman, 2018), design (Asojo, Kartoshkina, Jaiyeoba, \& Amole, 2019), and integrated into a study abroad program Esche (2018). The research presented here adds to this base of knowledge by exploring COIL-based learning in the emerging field of theory and practice focused on the creative economy. Similar to previous studies, this COIL project highlights approaches in which students "learn-by-doing" in cross-cultural teams, which appears effective in developing intercultural competencies. The specifics of the approach include icebreakers, holding constructive conversations, avoiding stereotypical depiction of others, and using common topics such as food, festivals, history, play, and humor to locate common ground.

Beyond just intercultural learning, COIL facilitates learning "in and with" the creative economy. Developing products and services in the creative economy requires individuals to possess the skills and abilities to create, discuss, debate, and negotiate (Gilmore \& Comunian, 2016; Harte et al., 2019; Luckman, 2013) regarding the values that the innovation intends to preserve, advance, or challenge (Davies \& Sigthorsson, 2013; Klamer, 2011). Therefore, it is crucial to develop a deep understanding of one's cultural predispositions, apart from the cultures and values that underpin the innovation.

The findings of this study reveal what is needed to help nurture entrepreneurs and workers in the creative economy. COIL-based learning can create micro-experiences allowing learners, through their actions and reflections, to appreciate the centrality of their values and those upheld by their communities when operating in the creative economy.

The research shows that when individuals from diverse cultural contexts engage in open constructive dialogue around cultures and values, it opens the space to conceptualize new products and services. Cross-cultural interactions can be a source of motivation for individuals to pursue creative entrepreneurship or careers as creative workers. The research also suggests that, when startup teams involve more than one individual (as is often the case in the creative economy), the innovation must bear cultural significance for each member of the team for most productive outcomes. These findings have profound implications on how COIL can be leveraged to teach creative economy in higher education. This study was an ex-post assessment of a single project, and further research that includes a control group is needed to clarify the effectiveness of the COIL-based approach to teaching and learning relative to the creative economy.

\section{Acknowledgments}

The author is thankful to the administration, faculty, and teaching assistants from Ocean University of China (Qingdao, China) and the University of Minnesota Duluth (Duluth, Minnesota, USA) for the joint planning and delivery of this COIL project. Minnesota-Duluth. The author also thanks Dr. Weiqing Zhang, Associate Professor, Chinese Area Studies at the University of Minnesota Duluth, for facilitating the partnership and participating in the planning of the project. Additional thanks are owed to the technical support staff at both 
universities to facilitate the initial setup of the classrooms and for on-call support. The study was partially funded by COIL cohort faculty development funds awarded by the University of Minnesota to the author.

\section{References}

Andrew, J., \& Luckman, S. (2015). Promoting the making self in the creative micro-economy. Paper presented at the Australia Council of University Art and Design Schools conference proceedings, Adelaide, Australia.

Ashton, D., \& Noonan, C. (2013). Cultural work and higher education Cultural work and higher education (pp. 1-21). London: Palgrave Macmillan. https://doi.org/10.1057/9781137013941

Asojo, A. O., Kartoshkina, Y., Jaiyeoba, B., \& Amole, D. (2019). Multicultural learning and experiences in design through Collaborative Online International Learning (COIL) Framework. Journal of Teaching and Learning with Technology, 8(1), 5-16. https://doi.org/10.14434/jotlt.v8i1.26748

Bennett, J. M. (2008). Transformative training: Designing programs for culture learning. In M. A. Moodian (Ed.), Contemporary leadership and intercultural competence: Understanding and utilizing cultural diversity to build successful organizations (pp. 95-110). CA: Sage: Thousand Oaks. https://doi.org/10.4135/9781452274942.n8

Brockbank, A., \& McGill, I. (2007). Facilitating reflective learning in higher education. McGraw-Hill Education (UK).

Creswell, J. W. (2009). Research design: Qualitative, quantitative, and mixed methods approaches (Vol. 4). Sage Thousand Oaks, CA.

Davies, R., \& Sigthorsson, G. (2013). Introducing the creative industries: From theory to practice. SAGE Publications Limited.

Esche, M. (2018). Incorporating Collaborative Online International Learning (COIL) into study abroad courses: A training design.

Gilmore, A., \& Comunian, R. (2016). Beyond the campus: Higher education, cultural policy and the creative economy. International journal of cultural policy, 22(1), 1-9. https://doi.org/10.1080/10286632.2015.1101089

Ginsburgh, V. A., \& Throsby, D. (2006). Handbook of the Economics of Art and Culture (Vol. 1). Elsevier. https://doi.org/10.1016/S1574-0676(06)01040-4

Harte, D., Long, P., \& Naudin, A. (2019). The university as intermediary for the creative economy: Pedagogues, policy-makers and creative workers in the curriculum. Arts and Humanities in Higher Education, 18(2-3), 120-139. https://doi.org/10.1177/1474022218824562

Holden, J. (2004). Capturing cultural value: How culture has become a tool of government policy.

Jacobs, D., \& Rookus, T. (2015). Experiences with a practice-oriented minor at ArtEZ Institute of the Arts. In O. Kuhlke, A. Schramme, \& R. Kooyman (Eds.), Creating Cultural capital: Cultural entrepreneurship in theory, pedagogy and practice (Vol. 1, pp. 253-259). Delft, The Netherlands: Eburon Academic Press.

Jie, Z., \& Pearlman, A. M. G. (2018). Expanding access to international education through technology enhanced Collaborative Online International Learning (COIL) courses. International Journal of Technology in Teaching and Learning, 14(1), 1-11.

Kahn, H. E., \& Agnew, M. (2017). Global learning through difference: Considerations for teaching, learning, and the internationalization of higher education. Journal of Studies in International Education, 21(1), 52-64. https://doi.org/10.1177/1028315315622022

Kan, K. H. (2011). Meeting Face to Face= Seeing Eye to Eye?: Interglobal Dialogue via Videoconference. International Journal of Education \& the Arts, 12(10), 10.

Kimmel, K., \& Volet, S. (2012). University students' perceptions of and attitudes towards culturally diverse group work: Does context matter? Journal of Studies in International Education, 16(2), 157-181. https://doi.org/10.1177/1028315310373833

Klamer, A. (2002). Social, cultural and economic values of cultural goods. Paper presented at the Conference of the Association for Cultural Economics International, Rotterdam.

Klamer, A. (2011). Cultural entrepreneurship. The Review of Austrian Economics, 24(2), 141-156. https://doi.org/10.1007/s11138-011-0144-6 
Leask, B. (2013). Internationalizing the curriculum in the disciplines-Imagining new possibilities. Journal of Studies in International Education, 17(2), 103-118. https://doi.org/10.1177/1028315312475090

Levick-Parkin, M. (2014). Creativity, the muse of innovation: how art and design pedagogy can further entrepreneurship. Industry and Higher Education, 28(3), 163-169. https://doi.org/10.5367/ihe.2014.0202

Levine, I., \& Shtern, J. (2015). Cultural and Creative entrepreneurship by Design. In O. Kuhlke, A. Schramme, \& R. Kooyman (Eds.), Creating cultural capital: Cultural entrepreneurship in theory, pedagogy and practice (Vol. 1, pp. 214-223). Delft, The Netherlands: Eburon Academic Press.

Luckman, S. (2013). Precariously Mobile: Tensions between the Local and the Global in Higher Education Approaches to Cultural Work. In D. Ashton \& C. Noonan (Eds.), Cultural work and higher education (pp. 69-86). London: Palgrave Macmillan. https://doi.org/10.1057/9781137013941_4

Mahlangu, I. (2015). Product Development Training as a Toll for Empowerment in Crafts. In O. Kuhlke, A. Schramme, \& R. Kooyman (Eds.), Creating cultural capital: Cultural entrepreneurship in theory, pedagogy and practice (Vol. 1, pp. 341-353). Delft, The Netherlands: Eburon Academic Press.

O’Brien, A. J., \& Eriksson, A. (2010). Cross-cultural connections: Intercultural learning for global citizenship. Intercultural Communication Competence. Educating the Global Citizen, 1-19.

Penna, K., Tinoco, J., \& Taylor, E. (2015). New Teaching and Learning Approaches to Creative entrepreneurship for Heritage Conservation Training Programs in Brazil. In O. Kuhlke, A. Schramme, \& R. Kooyman (Eds.), Creating cultural capital: Cultural entrepreneurship in theory, pedagogy and practice (Vol. 1, pp. 302-311). Delft, The Netherlands: Eburon Academic Press.

Pratt, A. C. (2008). Locating the cultural economy. In H. Anheier, \& Y. Isar (Eds.), The cultures and globalization series (Vol. 2, pp. 42-51). Thousand Oaks, CA: Sage. https://doi.org/10.4135/9781446247174.n4

Saintilan, P., \& Schreiber, D. (2017). Managing organizations in the creative economy: Organizational behaviour for the cultural sector. Routledge. https://doi.org/10.4324/9781315645032

Strasser, R. (2015). Graduate Music Industry Education: A holistic approach to program creation. In O. Kuhlke, A. Schramme, \& R. Kooyman (Eds.), Creating cultural capital: Cultural entrepreneurship in theory, pedagogy and practice (Vol. 1, pp. 122-131). Delft, The Netherlands: Eburon Academic Press.

Summers, M., \& Volet, S. (2008). Students' attitudes towards culturally mixed groups on international campuses: Impact of participation in diverse and non-diverse groups. Studies in higher education, 33(4), 357-370. https://doi.org/10.1080/03075070802211430

Tafra, M., Skledar, A., \& Jemric, I. (2015). The Impact of Blended Learning on Students' Skills and Competencies: The University of Applied Sciences Baltazar, Croatia. In O. Kuhlke, A. Schramme, \& R. Kooyman (Eds.), Creating Cultural capital: Cultural entrepreneurship in theory, pedagogy and practice (Vol. 1, pp. 141-150). Delft, The Netherlands: Eburon Academic Press.

Toner, M. (2018). Global connections, staying local. International Educator, 27(2), 24-27.

Unctad. (2010). Creative economy: A feasible development option. UNCTAD.

Vecco, M. (2015). A new approach to teach and learn cultural entrepreneurship. In O. Kuhlke, A. Schramme, \& R. Kooyman (Eds.), Creating cultural capital: Cultural entrepreneurship in theory, pedagogy and practice (Vol. 1, pp. 232-241). Delft, The Netherlands: Eburon Academic Press.

Zalewski, P., \& Parowicz, I. (2015). Dare to try! Waking the entrepreneurs in heritage conservators. In O. Kuhlke, A. Schramme, \& R. Kooyman (Eds.), Creating cultural capital: Cultural entrepreneurship in theory, pedagogy and practice (Vol. 1, pp. 260-270). Delft, The Netherlands: Eburon Academic Press.

\section{Copyrights}

Copyright for this article is retained by the author(s), with first publication rights granted to the journal.

This is an open-access article distributed under the terms and conditions of the Creative Commons Attribution license (http://creativecommons.org/licenses/by/4.0/). 